\title{
Employer Branding in Selected Companies in United Arab Emirates
}

\author{
Jawahitha Sarabdeen, Nada El-Rakhawy and Haneen Niaz Khan
}

University of Wollongong in Dubai, United Arab Emirates

\begin{abstract}
The article is an attempt to analyze the concept of employer branding and apply the concept to selected companies in United Arab Emirates (UAE). The concept of employer branding is drawn upon pre-existing theories, models, and practices across fields of marketing, human resource management and organizational behaviour. Various literature from marketing, organisational behaviour and human resource management were analysed to built the conceptual framework then three companies were selected to illustrate adoption of employer branding in United Arab Emirates. The research method used in the research paper is content analysis. The analysis shows that employers in the region do engage in employer branding initiatives.
\end{abstract}

Keywords: employer branding; human resource management; United Arab Emirates

\section{Introduction}

This article aims to analyze the recent literature findings and development regarding employer branding and apply those findings to the selected companies in UAE to elaborate the adoption of employer branding in those companies. A conclusion is derived as to whether the research supports or refutes the assertion of existence of employer branding in the companies in UAE.

\section{Method}

Review of scholarly journal articles, books and other research materials from the domain of marketing, human resource management and organizational behaviour was utilized to find evidence of theories and models to support or refute the nature of employer branding. On gathering the required information, the researchers have applied the theories to real organizations from different industries that provide real illustrative examples of the extent of employer branding applications in the UAE, the approaches used in those companies, and the resulting impact in the society. The researchers collected information from the websites of three companies chosen and conducted informal interviews on companies where information on their websites was inadequate.

\section{Defining Employer Branding}

As defined by the American Marketing Association, a brand refers to 'a name, term, sign, symbol, or design, or combination' to distinguish the goods/services of one company from another (Schneider, 2003), This essentially provides the organization with its 'public image, character, or personality' The principle of branding, though most commonly associated with marketing, has received rising interest in the human resource management field (Edwards, 2006:266; CIPD, 2007); more specifically, employer and employee branding. A wide array of practitioners and academics have contributed to the literature regarding employer branding (CIPD, 2007; Edwards, 2010).

Copyright (C) 2011 Jawahitha Sarabdeen, Nada El-Rakhawy and Haneen Niaz KhanAli. This is an open access article distributed under the Creative Commons Attribution License unported 3.0, which permits unrestricted use, distribution, and reproduction in any medium, provided that original work is properly cited. Contact author: Jawahitha Sarabdeen E-mail: jawahithasarabdeen@uowdubai.ac.ae 
Martin and Beaumont summarize the term employer branding as the image as seen through the eyes of its associates and potential hires' (Edwards, 2006:271). This implies that employer branding is a longterm commitment targeting both existing employees and finding ways to retain their talents and contributions, as well as appealing to the targeted talents available in the pool of new recruits. This is largely facilitated by conveying reasons to be perceived as an 'employer of choice' (Herman and Gioia, 2001).

Graeme Martin presents employer branding as a 'storyline' (Martin, 2007:18) highlighting the main elements (see Table1). The process of employer branding begins by creating a brand image for the employer, conveying an honest and accurate message as to its 'functional, economic and psychological benefits' (Martin, 2007:19); (see section 4.0). This supports Edwards (2006:273) and Backhaus and Tikoo (2004) who suggest that an organization needs to begin with developing its 'value proposition'.

According to the literature, communication is an essential element in establishing 'value proposition' (Backhaus and Tikoo, 2004) in the branding activities the employer undertakes (Edwards, 2006:273). The 'value' is communicated to the sought-after potential hires through the activities of external marketing. The 'value' is also communicated within the organization through its internal marketing efforts; aiming to embed the proposed value in the organization's culture, thereby enabling congruence between what has been 'promised' to what is actually carried out (Backhaus and Tikoo, 2004). In turn, this increases the commitment of the workforce (Edwards, 2006:273).

\section{Employer Branding - Underlying Theories}

Researchers have yet to identify a distinct theory or framework on the concept of employer branding. However, as more attention is diverted towards employer branding, recent research and scholars propose theoretical foundations; drawn upon existing theories developed in human resource management, organizational behaviour, and marketing to support the definition of employer branding and its underlying assumptions.

\section{Resource-Based View}

One of the underlying assumptions of employer branding coincides with the resource-based view (Backhaus and Tikoo, 2004). This theory suggests an alternative to implementing universal 'best-practices', an organization can derive its own competitive advantage by developing a set of unique 'internal resources' (Armstrong and Baron, 2002:9) that are rare and non-substitutable (Barney, cited in Backhaus and Tikoo, 2004; Armstrong and Baron, 2002:9). This theory is based on economic foundations of competitive advantage and scarce resources (Mankiw, 2004:4), supporting the claim that employer branding is a means to win the war for talent.

This competitive advantage can be achieved by directing attention towards the necessary human resource-led activities, aligned at a strategic level, and effective communication messages.

\section{Instrumental-Symbolic Frameworks}

Instrumental and symbolic frameworks also provide a basis for the notion of employer branding. Lievens and Highhouse (2003) have supported this relation.

This framework also has parallel roots within the marketing literature. This basic foundation is used in the context of brand image (Lievens and Highhouse, 2003). Based on the brand image of the employer and the employer reputation (see Figure 1 \& 2), employees create their perceptions of the brand. These are basically the reflections of two (instrumental and symbolic) attributes associated with the employer brand. 
The symbolic attributes comprise of the perceptions and emotions associated with the brand (Martin, 2007:19). As they are based on inferences (Lievens and Highhouse, 2003), consistent and accurate communications are required to minimize gaps in perceptions. These are intangible and abstract, and include elements such as prestige, innovativeness, organizational culture and management styles (Backhaus and Tikoo, 2004). Symbolic benefits also address an employee's need to fulfill his selfidentity (Lievens and Highhouse, 2003; Backhaus and Tikoo, 2004); implying the importance of person-job fit. Instrumental attributes, on the other hand, refer to those benefits which an employee gains from the employer, in terms of tangibles (Martin, 2007:19). These include pay and the means to achieve personal benefits (Lievens and Highhouse, 2003). However, as people generally tend to associate human traits to brands (Lievens and Highhouse, 2003) symbolic functions have a large impact. A combination of both should be considered in building employer branding.

\section{Psychological Contract}

Amber and Barrow view employer branding from a benefits perspective, namely functional, economic and psychological benefits that the employer provides its employee (Backhaus and Tikoo, 2004). The employer brand communicates its 'promise'. Thus the psychological contract is also considered as one of the critical theories involved in employer branding.

The term 'psychological contract' was first put forward by Argyris (Lewis, Thornhill, and Saunders, 2003:12). He states that psychological contract is basically the expectations employers have of their employees as well as those held by employees towards their employers (Lewis et al, 2003:12). This contract is 'unwritten' and may not be explicitly defined (Lewis et al, 2003:12). Thus the psychological contract is largely based on perceptions and expectations of the employment shaped by the image and the 'promise' put forward by the organization through its employer branding efforts (Davies, 2008).

\section{Increasing Importance of Employer Branding In Human Resource}

Based on the literature review, employer branding is increasingly gaining importance; implying that an HR function should take it into consideration (Edwards, 2006:266), for achieving a more strategic focus. As employer branding aims to 'win the war for talent' (Ulrich, cited in Edwards, 2006:266), both existing and potential employees are targeted. Building employer branding has implications on the role of HR function in employee induction, training and development and performance management as well as some aspects of employee relations (Edwards, 2006:266).

Additionally, business trends indicate that nowadays organizations are faced with increasing pressure from current and potential employees to be corporate socially responsible along with the need for firms to establish a unique selling proposition in employment terms for successfully winning the 'war for talent' (Jenner and Taylor, 2007:7-8). Consequently, it is predicted that future CEOs will spend less time with the investment community and give more preference to managing their organization's reputation as an employer (Barrow, 2007:13).

Employer branding has recently emerged as an influential approach to HR management in many countries across the globe (Jenner and Taylor, 2007:7) because strong employer brands represent valuable resources which can allow organizations to gain a long-term distinctive competitive advantage for outcompeting rivals (Balmer and Gray, 2003:1). Therefore, the above findings suggest that employer branding is likely to be the future of HR, rather than a fad. 


\section{Future of Employer Branding}

Employer branding integrates the business needs and is used strategically and operationally to influence potential, current and ex-employees along with other stakeholders. Employer branding is inevitable looking at the changing demographics, technological advances and global economy. These factors collectively influence organizations to reconsider that traditional HR approach and skills are not capable of tackling the new environment. Hence HR requires a reorientation (Hosley, 2007). So far, many organizations adopt employer branding in an ad hoc basis except innovative organizations where they need to attain mastery over the current environment. The employer branding gives them a competitive advantage to attract, retain and get most from the employees. It also induces affinities and loyalty. The future of employer branding is where employer value proposition will be created in alignment with strategy and other vital business processes. Researches show that the employer branding requires employers to participate in local and mainstream industry awards, introduce initiatives like the employee of the month, publishing employee testimonials and arrange employee ambassadors (Martin, 2007). The employer also should provide opportunities for learning and development, allocate appropriate reward and recognition (Martin, 2007). In addition, the employer brand building requires healthy and corporate work environment that provides opportunity for work and life-balanced initiatives. Google and Microsoft established their branding because they have adopted many of those requirements (Stone, 2005:27).

The future of employment branding depends on: How joined-up an organization is in its approach? It should go beyond HR and the CEO also should care about it. It becomes the organizational responsibility and opportunity. Royal Philips Electronics of the Netherlands which has 121,000 employees in 60 destinations is a successful adopter of employer branding (House, 2007). It also depends on how brand plays out inside the organization (House, 2007)|.

However, it is to be noted that there is not enough metrics and hard evidence to support that the employer branding has delivered business results. This may be due to it being an "ongoing journey" and would be difficult to produce overnight or quick results in figures and tables. This could cause difficulties in convincing management to inject more money as an investment. Perhaps it is necessary to set key priorities and opportunities areas like Philips Company so that the organizations could develop a set of measures for each phase of the area of priority (Jenner and Taylor, 2007).

\section{Employer Branding in the UAE}

Employer branding is still a relatively new concept, nevertheless it is gaining increasing attention and application in the UAE and the wider Middle Eastern region. Employer branding is widely implemented by multinational companies operating in the Gulf region, in addition to locally-established companies in the UAE, as explained below:

\section{Nestle in the Middle East (NME)}

NME has long been established as a top food, beverage, nutrition, health and wellness company projecting a corporate brand of excellence that aims to provide consumers with world-class products and services (NME, 2008:4). NME is also founded on a universal corporate philosophy of 'Good Food, Good Life' (NME, 2008:4) upon which the employer branding strategies are based.

One significant aspect relates to the promotion of a desirable 'employer of choice' image targeting current and potential employees. This is reflected in NME's training and development activities as Nestle strongly believes that employees form the strength and 'nothing can be achieved without their commitment and energy' because people are regarded as 'the most important asset' (NME, 
2008:40). To this extent, Nestle has invested over $\$ 1.5 \mathrm{~m}$ in staff training and support in the Middle East region, indicating that NME is a 'people company' through its commitment to offering employees opportunities to develop their capabilities, whereby they realize their full potential (NME, 2008:40), This company-wide belief is further translated into three main axes (NME, 2008:40): talent management; enabling employees to build valuable work experience through exposure from overseas assignments, on-the-job training, or project participation; fostering meaningful learning opportunities to simultaneously enhance professional and personal performances.

Another aspect is NME's contribution to corporate social responsibility which emanates from within. This involves fun activities and events that emphasize the importance of healthy lifestyle habits whilst establishing a sense of belonging (NME, 2008:42), satisfying social needs of employees. For example, organizing numerous team-building activities such as marathons, football matches, and 'good eating habits' and in-house training (NME, 2008:42). Moreover, to give back to society, NME organizes blood-donation drives and regularly works with local charity organizations to help in raising relief funds (NME, 2008:44). The company participated in Dubai Cares campaign by contributing to the building of two schools for 1000 students; helped in the restoration of Syrian historical sites to promote cultural preservation (NME, 2008:46).

\section{The Emirates Airlines Group (EA)}

EA, one of the divisions of 50 companies of Emirates Groups, was established in 1985, growing rapidly to cover 62 countries (EA, $2010)$. It is rated as one of the 20 profitable airlines in the world and won more than 400 international awards (EA, 2010). It has built an international "people focused" employer reputation that operates environmentally friendly and technologically advanced fleets (EA, 2010).
The following features facilitated EA in building its employer brand (EA, 2010):

Employee Recruitment: People from 150 countries are recruited in EA. The company follows various selection tools to make sure that work force is of a high calibre and contributes to the success of the company. EA portrays its image as "people" organization and clearly places people as one of its core value of business.

Development and Training: It adopts Plateau Learning Management System for staff development and training purposes as it possesses a learner-centric approach by empowering individuals to take responsibilities for their own learning and development.

Employee Reward and Recognition: Employee reward and recognition are given particular importance, as special allowances, increment and bonuses are allocated on an equitable and fair basis.

Remuneration: Various remuneration packages are provided for the employees. There are cash and non-cash aspects of remuneration. It provides a competitive tax free basic salary, accommodation, transport allowances, profit sharing options for senior executives plus professional specialist allowances. It also provides an exchange protection scheme under cash remuneration packages. Non-cash benefits include annual leave, gratuity, tickets, educational allowances, insurance, workmen compensation and medical coverage. All these components will ensure that employees' interests are looked after so that they are committed to the employer brand.

Website: The EA website is very interactive which provides all necessary information for the visitors, investors and employees. The career portal facilitated international talents to be reached and it also helps to disseminate consistent and uniformed information irrespective of the location. 
Corporate Social Responsibility: It tries to portray an eco-friendly company image as it uses relatively fewer resources and less carbon footprint. It started with eco-friendly company campaign where it shows that the company is operating based on three aims selecting and operating most eco-friendly fleets, to transform the whole organization's operations as eco-friendly, be an eco-friendly leader in the region. As per these aims, EA links strategically its various departments like operation, finance, people and customers with eco-friendly initiatives.

Leadership: Leadership support is an important condition in employer branding. The leadership of EA is very supportive. For example Gary Capma, President of Group Services and Dnata stated that employees are the key for success that is the reason why the Emirates Group provides various vocational training and development. Similarly, Maurice Flanagan the President of EA and group emphasized that their employees are the main cause for the company and that is the reason they select them carefully.

Diversity of Workforce: EA considers diversity of work force as strength as they could bring together new ideas, innovation and new thinking styles. The diversity is one of the factors for its business success.

Even if there is no set metrics to measure the employer branding, the public perception, the employer loyalty and the low turnover rate, with the exception of air-crew, plus the large number of applications they receive provide evidence of successful employer branding and favorable corporate reputation. The EA employer brand has been gradually built upon, since its inception (EA, 2010).

\section{Gulf Food Trade (GFT)}

This organization has been established in 2001 as the authorized distributor of Mars GCC products within the United Arab Emirates (GFT, 2010a). GFT has grown to employ over 180 employees (both office and field based) (GFT, 2010b). From the discussions with employees at the GFT office, it was concluded that GFT does employ activities and initiatives to build its brand. A few examples are as follows:

With regard to the existing employees, employee well-being is greatly emphasized. Health and nutrition initiatives are demonstrated by introducing 'fruits and vegetables' day; here, once a week, prepared packs of freshly cut fruits and vegetables are distributed amongst all employees. Furthermore, employees are encouraged to join the company sport teams (cricket; basketball), where matches are set against other companies. This allows for socialization and engagement. Other personal well-being services provided include financial planning advice and yoga classes. Career development is also promoted. Employees can progress upwards as well as cross-functionally. Also, as the company continues to grow, new projects are developed, and employees are able to take part of such projects, and work in teams with others from different departments.

As for potential employees, the hiring process assumes several steps. For instance, when considering candidates for the merchandiser position, a tour with one of the current merchandisers is compulsory, before the job offer is proposed. Here, the candidate is able to experience and observe a 'typical day' for the job. This corresponds to the realistic job preview, whereby the company tries to reduce expectation gaps. Also, in relation to psychological contracts and what the potential employee is to expect once employed, the candidate is briefed on the well-being initiatives undertaken by the company. Furthermore, on the careers webpage a short profile about a current GFT employee and his history at the company is included. Recently, the profile was related to an employee who described how he has grown and moved from being a merchandiser to an account manager (GFT, 2010c). This further demonstrates to potential employees that the company does follow on its 'promise'. 
The above three examples demonstrate the existence of employer branding in the UAE and the Middle Eastern region. With the exception of air-crew turnover rates, the activities undertaken by the companies have provided thus far positive results. Regarding air-crew turnover, a deeper analysis into the underlying causes is required. A main suggestion is to consider each activity (in relation to employer branding) that Emirates Airlines assumes and compare it against its value to the air-crew as well as the perceptions of the air-crew members, thereby identifying perceptual gaps. This could be a starting point for explanations or adjustments to better suit the requirements and psychological contracts between the aircrew and Emirates Airlines.

\section{Conclusion}

The notion of employer branding does in fact exist. Though there is no concrete theory or model of employer branding, the concept draws on existing theories and practices across varying fields; namely marketing, human resources management, and organizational behavior. Some of the underlying theories and principles considered throughout the article are the psychological contracts and realistic job previews, which aim to reduce expectation gaps between employees and employers, thereby reducing dissatisfaction and withdrawal. In addition, the instrumentalsymbolic framework is applied, as it considers brand perceptions and its relation to employee need-fulfillment as well as the tangible aspects of a job.

Within the UAE and the Middle Eastern region, employer branding efforts have been observed. Perhaps, not to the same extent, but the three examples used in the report show that the companies are aware of the importance of their reputation. Thus far, with the exception of air-crew turnover, the activities employed appear to have been beneficial.

\section{References}

Adler, R.B. \& Elmhorst, J. M. (2008). Communicating at Work: Principles and Practices for Businesses and the Professions, (9th ed.). Boston: McGraw Hill.

Armstrong, M. \& Baron, A. (2002). Strategic HRM: The Key to Improved Business Performance, London: The Chartered Institute of Personnel and Development.

Backhaus, K. \& Tikoo, S. (2004). "Conceptualizing and Researching Employer Branding," Career Development International, 9 (4/5) 501-517. www.emeraldinside.com

Balmer, J. M. T. \& Gray, E. R. (2003). "Corporate Brands: What are They? What of Them?," European Journal of Marketing, 37 (7/8) 972-997. www.emeraldinside.com

Barrow, S. (2007). 'The Future of Employer Branding and HR?,' London: Research Insight - The Chartered Institute of Personnel and Development, 12-14

CIPD (2007). "Employer branding: The Latest Fad or the Future for HR?," London: The Chartered Institute of Personnel and Development, 1-24

Davies, G. (2008). "Employer Branding and Its Influence on Managers," European Journal of Marketing, 42, 5/6, 667-681. www.emeraldinside.com

EA (2010).'Emirates United Arab Emirates,' Emirates.

http://www.emirates.com/ae/english/

Edwards, M. R. (2006). "Employer and Employee Branding: HR or PR?," in Managing Human Resources: Personnel Management in Transition, (4th ed.). ed. S. Bach, Malden, Mass: Blackwell Publishing, pp. 266-286.

Edwards, M. R. (2010). "An Integrative Review of Employer Branding and OB Theory," The Journal of Personnel Review, 39, 1, 5-23. www.emeraldinside.com 
Gatewood, R. D., Field, H. S. \& Barrick, M. R. (2008). Human Resource Selection, (6th int. ed.). Sydney: Thomson South Western.

GFT, (2010a). 'About Us,' Gulf Food Trade LLC. http://www.gftuae.com/gftuae/Aboutus.aspx

GFT, (2010b). 'Careers - Grow Your Career with Us,' Gulf Food Trade LLC. https://www.gftuae.com/gftuae/careers.asx

GFT, (2010c). 'Home,' Gulf Food Trade LLC. http://www.gftuae.com/gftuae/

Herman, R. E. \& Gioia, J. L. (2001). “Helping Your Organization Become an Employer of Choice," Employment Relations Today, 28, 2, 62-78. www.proquest.com

House, G. (2007). 'The Changing World of Employment Brands and HR,' London: Research Insight - The Chartered Institute of Personnel and Development, 10-13.

Housley, H. (2007). Harnessing Shift, London: Research Insight - The Chartered Institute of Personnel and Development, 15-17

Independent News and Media, (2009). 'Employer Branding Can Help Hold onto Talent Unknown,' The Argus, p.3

Jenner, S. \& Taylor, S. (2007). "Employer Branding - Fad or the Future for HR?," London: Research Insight - The Chartered Institute of Personnel and Development, 7-9.

Jones, G. R. (2010). Organizational Theory, Design and Change, (6th ed.). Upper Saddle River, NJ: Pearson/Prentice Hall.

Konig, C. (2008). "Employer Branding: Management Crunch," Brand Strategy, 1-4. www.proquest.com

Lake, L. (2003). "What is Branding and How Is it Important to your Marketing Strategy?," available at: http://marketing.about.com/cs/brandmktg/ a/whatisbranding.htm
Lievens, F. \& Highhouse, S. (2003). "The Relation of Instrumental and Symbolic Attributes to a Company"s Attractiveness as an Employer," Personnel Psychology, 56, 1, 75-102. www.proquest.com

Lewis, P., Thornhill, A. \& Saunders, M. (2003). 'Employee Relations: Understanding the Employment Relationship,' Harlow, Middlesex: Financial Times Prentice Hall.

Mankiw, N. G. (2004). Principles of Macroeconomics, (3rd ed.). Mason, Ohio: Thomson/South-Western.

Martin, G. (2007). 'Employer Branding Time for Some Long and "Hard" Reflection,' London: Research Insight - The Chartered Institute of Personnel and Development, 1823.

Maxwell, R. \& Knex, S. (2009). "Motivating Employees to 'Live the Brand': A Comparative Case Study of Employer Brand Attractiveness within the Firm," Journal of Marketing Management, 25, 9/20. www.proquest.com

Middle East Company News, (2009). 'Company Leaders are the Most Powerful Employer Branding Tools - Global Survey Findings,' 1-3. www.proquest.com

Moroko, L. \& Uncles, M. D. (2008). "Characteristics of Successful Employer Brands," Journal of Brand Management, 16 (3) 160-175. www.proquest.com

Mosley, R. W. (2007). “Customer Experience, Organisational Culture and the Employer Brand," Journal of Brand Management, 15 (2) 123-134. www.proquest.com

Myers, D. (2003). 'Psychology,' New York: Worth Publishers.

NME, (2008). 'Nestle in the Middle East Committed to a Better Tomorrow,' Dubai: Express Printing Services. Robbins, S. (2007). Organizational Behavior, (12th ed.). NJ: Pearson Prentice Hall. 
Rosethorn, H. \& Mensink, J. (2007). 'Employer Branding - More Than Just a Fashion Statement?,' London: Research Insight - The Chartered Institute of Personnel and Development, 4-6.
Stone, R. (2005). Human Resource Management, (5th Ed.). Sydney: John Wiley \& Sons Australia Ltd. 